\title{
Power Quality Improvement Using Unified Power Quality compensator
}

\author{
P. JANAKI ${ }^{1}$, M. ASIRI NAIDU ${ }^{2}$, V. MANEESHA ${ }^{3}$, M.V.V. SASIKANTH ${ }^{4}$, S. PRAVEEN KUMAR $^{5}$ \\ ${ }^{1}$ ASSOCIATE PROFESSOR, Department of EEE, Lendi Institute of engineering and technology,INDIA, \\ janaki.pakalapati@gmail.com \\ ${ }^{2}$ STUDENT, Department of EEE, Lendi Institute of engineering and technology, INDIA, \\ asirinaidumoida1234@gmail.com \\ ${ }^{3}$ STUDENT, Department of EEE, Lendi Institute of engineering and technology, INDIA, \\ maneesha.varanasi14@gail.com \\ ${ }^{4}$ STUDENT, Department of EEE, Lendi Institute of engineering and technology, INDIA, \\ sasikanth2605@gmail.com \\ ${ }^{5}$ STUDENT, Department of EEE, Lendi Institute of engineering and technology, INDIA, \\ praveensanapathi7@gmail.com
}

\begin{abstract}
Power quality has become an important factor in power systems, for consumer and household appliances with proliferation of various electric/ electronic equipment and computer systems. The main causes of a poor power qualityare harmonic currents, poor power factor, supply voltage variations, etc. In recent years the demand for the quality of electric power has been increased rapidly. Power quality problems have received a great attention nowadays because of their impacts on both utilities and customers. Voltage sag, swell, momentary interruption, under voltages, over voltages, noise and harmonics are the most common power quality disturbances.It proposes a new connection for a unified power quality compensator (UPQC) to improve the power quality of two feeders in a distribution system. It illustrates how UPQC can improve the power quality by mitigating all these PQ disturbances. The proposed configuration of the UPQC is developed and verified for various power quality disturbances by simulating the mode using MATLAB.
\end{abstract}

Key words: Power, UPQC, Power Quality

\section{INTRODUCTION}

Power quality is defined as any change in power (voltage, current and frequency) that interference with the normal operation of electrical experiment. There are many different reasons for the enormous increase in the power quality. Some main reasons are:

Electronic and power electronic equipment has especially become much more sensitive. Equipment has become less tolerant of voltage quality disturbances production stoppages. Equipment produces more current disturbances than it used to do. Both low and high- power equipment is more and more powered by simple power electronic converters which produce a broad spectrum of distortion. These are indications that the harmonic distortion in the power system is raising, but no conclusive results are obtained due to the lack of large-scale surveys. The deregulation of the electricity industry has led to an increased need for quality indicators. Customers are demanding, and getting, moreinformation on the voltage quality they can expect. Also, energy efficient equipment is an important source of power quality disturbances.
Adjustable speed drives and energy saving lamps are both important sources of waveforms distortion and are also sensitive to certain types of power quality disturbances. When these power quality problems become a barrier for the large-scale introduction of environmentally friendly sources and user equipment.

The main objective of electric utilities is to supply their customers an uninterrupted sinusoidal voltage of constant magnitude and frequency with sinusoidal balanced currents at the AC mains. However, present day AC distribution systems are facing severe power quality (PQ) problems such as high reactive power burden, unbalanced loads, harmonic-rich load currents, and an excessive neutral current. In addition, these utilities are not able to avoid the voltage sag, swell, surges, notches, spikes, flicker, unbalance, and harmonics in the supply voltages across the consumers' load end. There are many critical and sensitive loads that require uninterrupted sinusoidal balanced voltages of constant magnitude and frequency, otherwise their protection systems operate due to power quality disturbances.

\section{SYSTEM TOPOLOGY}

This chapter deals with an exhaustive analysis and design of UPQCs. The UPQCs can be classified in many ways, such as supply-based classification (e.g., two-wire, three-wire, and four-wire UPQCs), converter-based classification (e.g., VSCand CSC-based UPQCs), topology-based classification (e.g., right shunt UPQCs and left shunt UPQCs), classification based on the method of control (e.g., UPQC-Q: a Series compensator is used for series voltage injection in quadrature with supply current with almost zero active power injection; UPQC-P: a Series compensator is used for series voltage injection in phase with supply current with only an active power injection; UPQC$\mathrm{S}$ : a Series compensator is used for series voltage injection at optimum phase angle with minimum $\mathrm{kVA}$ rating, $\mathrm{S}$, or any other criterion decided by the requirement), and so on.

A UPQC, which is a combination of shunt and series compensators, is proposed as a single solution for mitigating multiple PQ problems. The power circuit of a UPQC consists of two VSCs joined back-to-back by a 


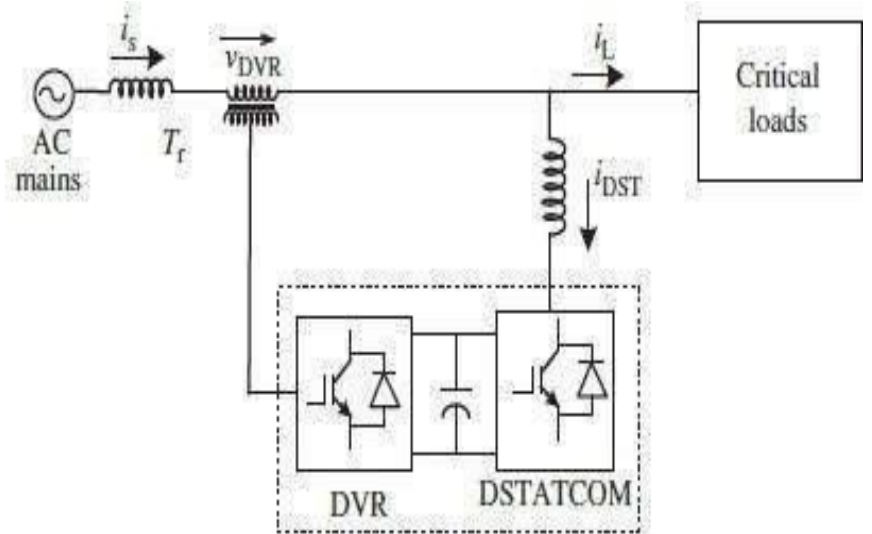

Figure 1: Shows A VSC-based unified power quality compensator.

common DC link. The shunt device known as the DSTATCOM provides reactive power compensation along with load balancing, neutral current compensation, and elimination of harmonics (if required) and is positioned parallel to the consumer load. The series device known as the Series compensator keeps the load end voltage insensitive to the supply voltage quality problems such as sag/swell, surges, spikes, notches, or unbalance. The Series compensator injects a compensating voltage between the supply and the consumer load, and restores the load voltage to its reference value. The cost of PQ to manufacturing and emergency services together with the requirement of improved power quality in the current waveform justifies the cost and complex control required for UPQCs. There are many control techniques and topologies reported for the control of UPQCs. Theory, modeling, control, and rating issues of UPQCs for load bus voltage control in distribution systems are reported in the literature [1-50]. An energy storage element at the DC bus is also used for the operation of an alternative unified power flow controller. The DSTATCOM and Series compensator are controlled separately for power quality enhancement in the current and voltage, respectively. Most of the control algorithms reported for the DSTATCOM and Series compensator are applied to the UPQC. The instantaneous reactive power theory, synchronous reference frame theory, fuzzy control algorithm, instantaneous symmetrical component theory, and neural network theory, among others, are some control approaches reported in the literature. The three-phase four-wire systems require a neutral current compensator along with other UPQC functions.

\section{PRINCIPLE OF OPERATION OF AN ACTIVE SERIES AND ACTIVE SHUNT BASED HYBRID POWER COMPENSATOR}

In general, this HPF (known as a universal APF) has two VSCs connected to a common DC bus, one VSC is connected in series (known as a series APF) with AC lines through an injection transformer and another VSC is connected in shunt (known as a shunt APF) normally connected across the consumer loads or across the PCC, as shown in Figure 3.3.2 as a combination of active series $\left(\mathrm{AF}_{\mathrm{Ss}}\right)$ and active shunt $\left(\mathrm{AF}_{\mathrm{Sh}}\right)$ compensators. Both the VSCs use HCC control; therefore, they require small ripple compensators to mitigate switching ripples. It requires Hall effect voltage and current sensors for feedback signals and normally a DSP is used to implement the required control algorithm to generate gating signals for the solid-state devices of both VSCs of the universal APF. The series VSC used as an active series compensator ( $\mathrm{AF}_{\mathrm{Ss}}$ ) is normally controlled in HCC voltage control mode to inject.
In general, this HPF (known as a universal APF) has two VSCs connected to a common DC bus, one VSC is connected in series (known as a series APF) with AC lines through an injection transformer and another VSC is connected in shunt (known as a shunt APF) normally connected across the consumer loads or across the PCC, as shown in Figure 3.3.2 as a combination of active series $\left(\mathrm{AF}_{\mathrm{SS}}\right)$ and active shunt $\left(\mathrm{AF}_{\mathrm{Sh}}\right)$ compensators. Both the VSCs use HCC control; therefore, they require small ripple compensators to mitigate switching ripples. It requires Hall effect voltage and current sensors for feedback signals and normally a DSP is used to implement the required control algorithm to generate gating signals for the solid-state devices of both VSCs of the universal APF. The series VSC used as an active series compensator $\left(\mathrm{AF}_{\mathrm{SS}}\right)$ is normally controlled in HCC voltage control mode to inject.

Appropriate voltages in series with the AC mains and the shunt VSC used as an active shunt (AFsh) compensator is normally controlled in HCC current control mode to inject appropriate. currents in parallel to the load in the system.

This universal APF is considered as a perfect solution for eliminating voltage harmonics at PCC and current harmonics produced by nonlinear loads. It is also capable of providing the compensation of other voltage- and current-based power quality problems but at the cost of additional rating and at an increased cost. This universal APF also needs many passive elements such as a DC bus capacitor, $\mathrm{AC}$ interacting inductors, injection and isolation transformers, and small passive compensators.

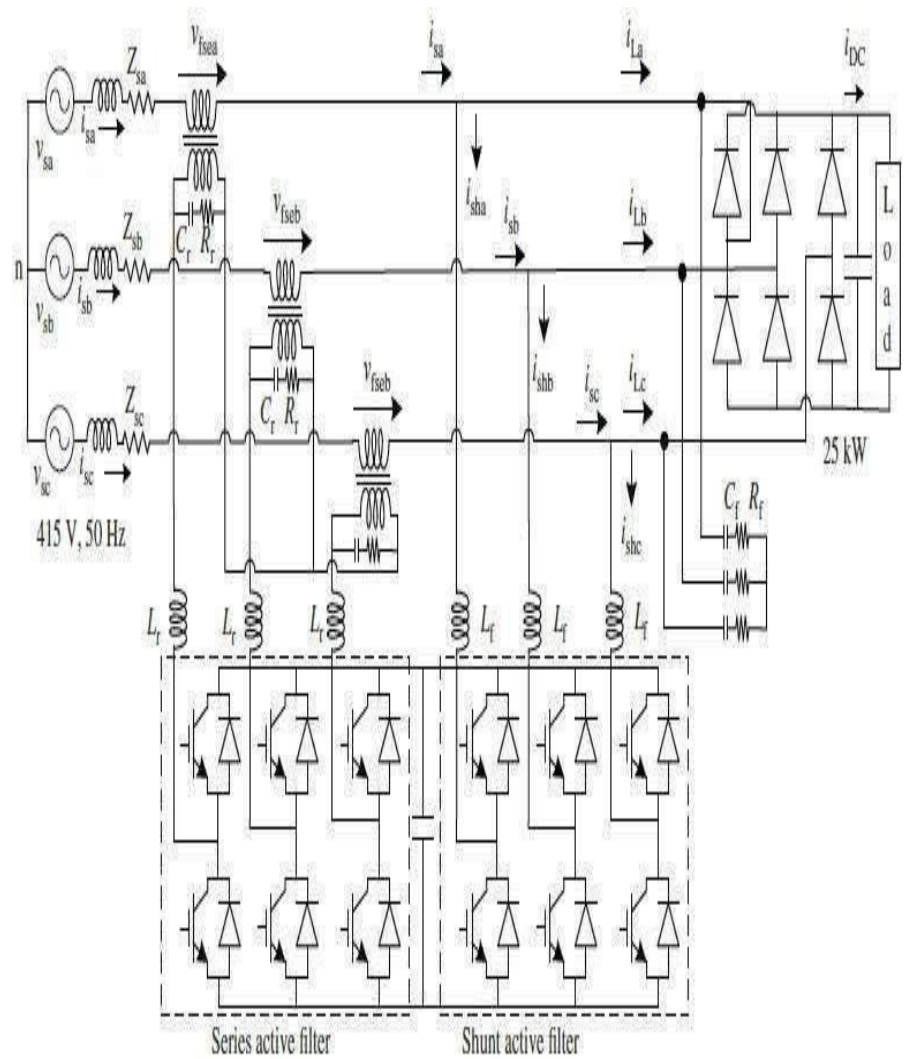

Figure 2: Shows Schematic diagram of active series and shunt -based hybrid compensator configuration 


\section{P-Q CONTROL ALGORITHM}

Reactive power (P-Q) theory to compensate the reactive power drawn by the load which helps in improving the power quality of the distribution network. p-q theory transforms the three- phase system of voltages and currents from phase coordinates to $0-\alpha-\beta$ coordinates by means of Clark-Concordia transformation, which is represented by the following matrices (1) and (2).

In the case of three-phase three-wire systems $\mathrm{Vo}=0$ and io $=0$. In the new co-ordinate system using stationary orthogonal reference frame theory, the instantaneous real and imaginary powers are expressed by the following matrix. The basic block diagram of the $p-q$ theory for reactive power compensation is shown in Fig.5.The control algorithm based on pq theory which compensates the reactive power and helps in improving the power factor is outlined hereunder. The three phase source voltages and source currents in a-b-c reference frame are transformed to the stationary orthogonal reference frame variables $(\alpha, \beta)$ using Clark-Concordia transformation as per equations (1), (2).

The reference currents are extracted from the instantaneous reactive power theory using instantaneous active reference power $\mathrm{p}^{*}$ and instantaneous reactive power reference $\mathrm{q}^{*}$.

The DC bus voltage control loop computes $\mathrm{p}^{*}$ as shown in Fig. 5. $\mathrm{q}^{*}$ is obtained from the computed reactive power from the measured three phase source voltages and currents. For reactive power compensation of the system, the instantaneous reactive power needs to be supplied by the DSTATCOM to improve the power factor of the system. Hence the reference currents $i_{\alpha}{ }^{*}$ and $i_{\beta} *$ are obtained from $\mathrm{V}_{\mathrm{s} \alpha}, \mathrm{V}_{\mathrm{s} \beta}, \mathrm{p}^{*}$ and $\mathrm{q}^{*} \mathrm{using}$ equation (4).These reference currents obtained are compared with actual source currents in orthogonal reference frame and processed through PI controllers to obtain the corresponding voltages $\mathrm{V}_{\alpha}$ and $\mathrm{V} \beta$ in orthogonal reference frame. By using inverse Clark's transformation $\mathrm{V}_{\alpha}, \mathrm{V} \beta$ are transformed back to the $a b-c$ reference frame quantities Viaref, Vibref and Vicref. These reference voltages are used for the generation of gate pulses for the IGBT based VSC which operate with level shifted sinusoidal pulse width modulation.

Gate pulses are generated for the voltage-based converter by comparing the level shifted in phase carrier waves with the reference voltage wave generated by the $p-q$ theory-based controller

$$
\begin{aligned}
& {\left[\begin{array}{l}
V_{o} \\
\mathrm{~V}_{\alpha} \\
\mathrm{V}_{\beta}
\end{array}\right]=\sqrt{\frac{2}{3}}\left[\begin{array}{ccc}
\frac{1}{\sqrt{2}} & \frac{1}{\sqrt{2}} & \frac{1}{\sqrt{2}} \\
1 & -\frac{1}{2} & -\frac{1}{2} \\
0 & \frac{\sqrt{3}}{2} & -\frac{\sqrt{3}}{2}
\end{array}\right]\left[\begin{array}{l}
V_{a} \\
V_{b} \\
V_{c}
\end{array}\right]} \\
& {\left[\begin{array}{l}
i_{0} \\
i_{\alpha} \\
i_{\beta}
\end{array}\right]=\sqrt{\frac{2}{3}}\left[\begin{array}{ccc}
\frac{1}{\sqrt{2}} & \frac{1}{\sqrt{2}} & \frac{1}{\sqrt{2}} \\
1 & -\frac{1}{2} & -\frac{1}{2} \\
0 & \frac{\sqrt{3}}{2} & -\frac{\sqrt{3}}{2}
\end{array}\right]\left[\begin{array}{l}
i_{a} \\
i_{b} \\
i_{c}
\end{array}\right]}
\end{aligned}
$$
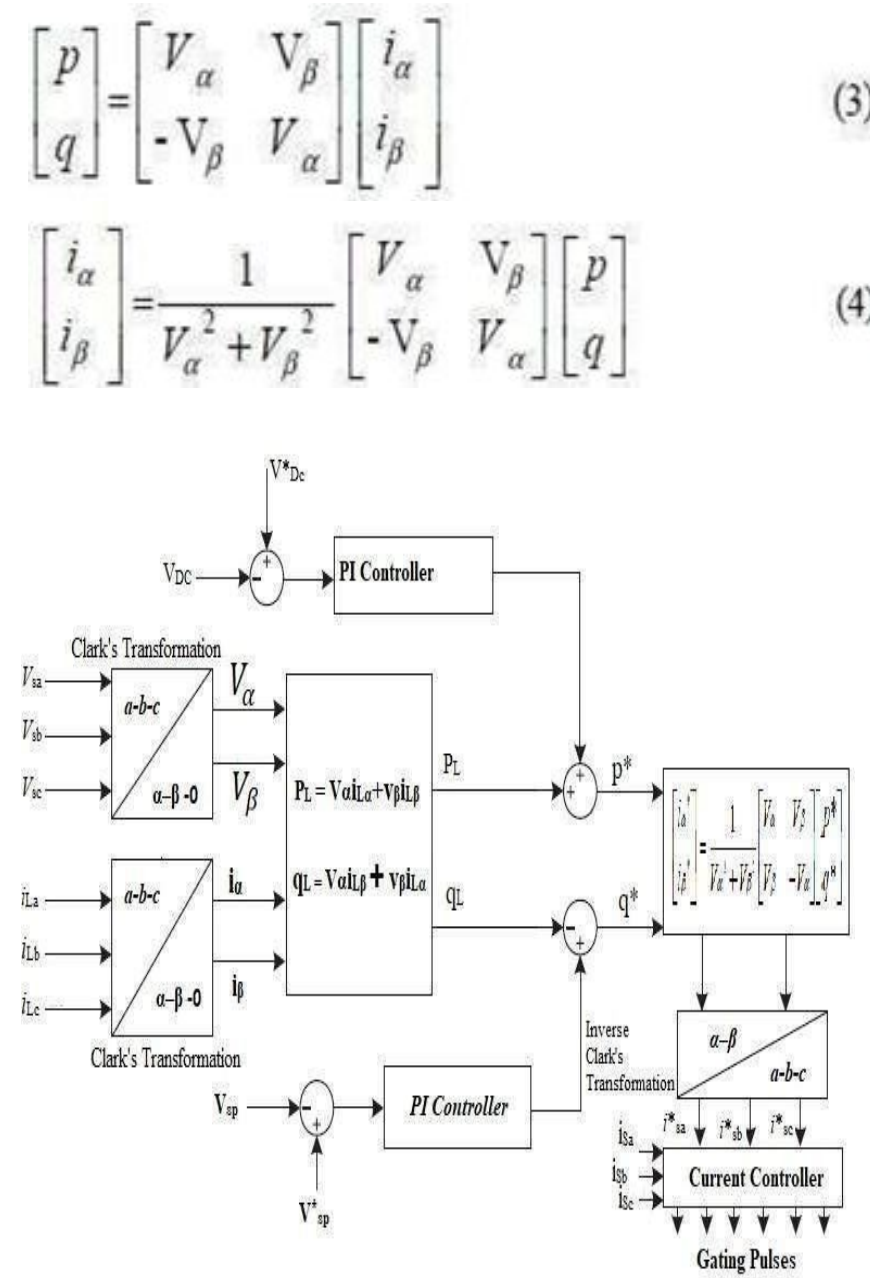

Figure 3: Shows Schematic diagram of PQ control technique

\section{HYSTERESIS CURRENT CONTROLLER}

Hysteresis current control is a method of generating the required triggering pulses by comparing the error signal with that of thehysteresis band and it is used for controlling the voltage source inverter so that the output current is generated from the filter will follow the reference current waveform.

This method controls the switches of the voltage source inverter asynchronously to ramp the current through the inductor up and down, so that it follows the reference current. Hysteresis current control is the easiest control method to implement in the real time. the ramping of the current between the two limits where the upper hysteresis limit is the sum of the reference current and the maximum error or the difference between the upper limit and the reference current and for the lower hysteresis limit, it is the subtraction of the reference current and the minimum error. Supposing the value for the minimum and maximum error should be the same. As a result, the hysteresis bandwidth is equal to two times of error. According to the operating principleof the inverter, the output voltages of each phase are significantto the switching pulses of the switches in each leg. As a result, the switching gates for the active power filter can be obtained. The voltage across the inductors show the frequency of the switching and the frequency can be altered by adjusting the width of the hysteresis tolerance band. 


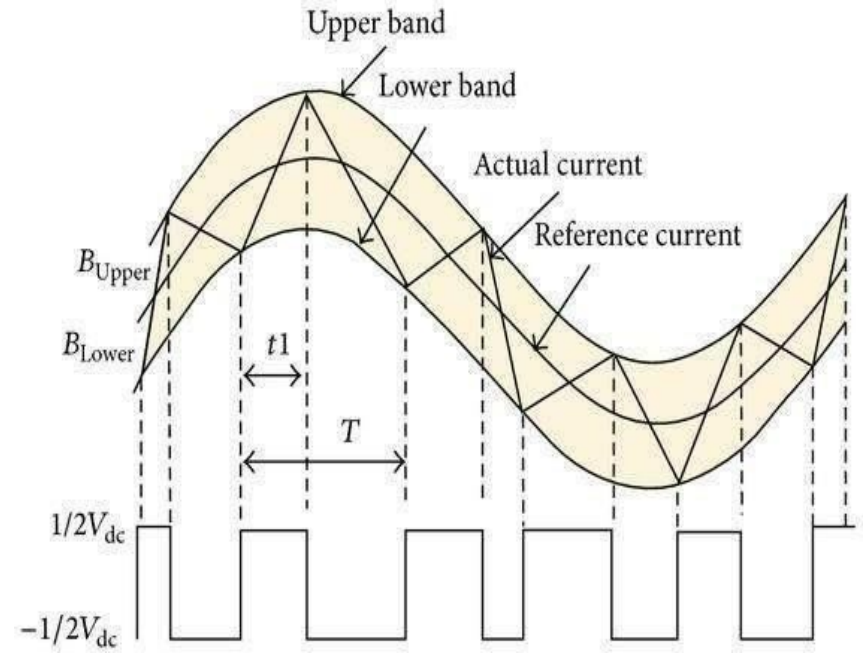

Figure:4 shows Hysterisis current controller

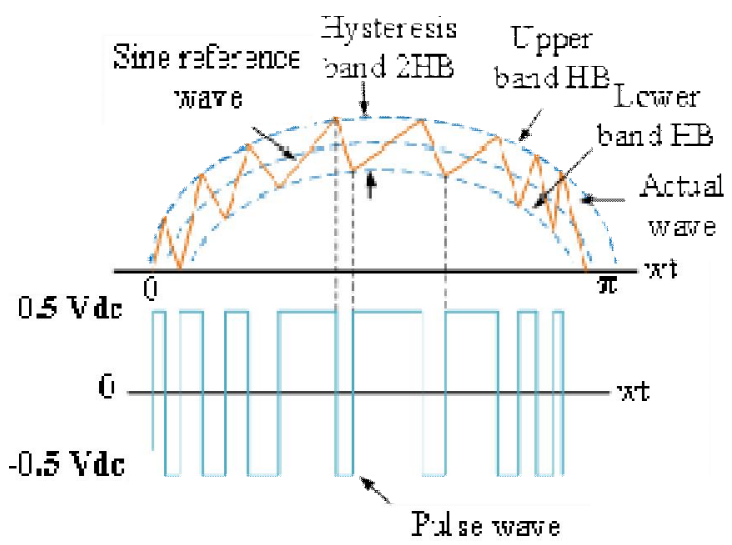

Figure:5 shows Hysteresis current controller waveform

\section{SIMULATION}

MATLAB is an interactive system whose basic data element is an array that does not require dimensioning. This allows you to solve many technical computing problems, especially those with matrix and vector formulations, in a fraction of the time itwould take to write a program in a scalar non interactivelanguage such as $\mathrm{C}$ or Fortran.

The name MATLAB stands for matrix laboratory. MATLAB was originally written to provide easy access to matrix software developed by the LINPACK and EISPACK projects, which together represent the state-of-the-art in software for matrix computation. MATLAB has evolved over a period of years with input from many users. In university environments, it is the standard instructional tool for introductory and advanced courses in mathematics, engineering and science.

Using the MATLAB/Simulink software several simulations are implemented to evaluate the proposed "Power Quality Improvement" based UPQC. Data used for simulation system are shown in Table 8.2. The following simulations correspond to a voltage with $10 \%$-third harmonic content with amplitude of $415 \mathrm{~V}$ and frequency of $50 \mathrm{~Hz}$. The voltage source supplies the parallel association of a non-linear load. The load current, without compensation shows above figures for this test it can be seen that the both voltage and current present a harmonic content. The shunt active filter of the UPQC is controlled to mitigate current harmonics and series active filter of the UPQC is controlled to mitigate voltage harmonics, in this way, it is expected that the source current and voltage becomes sinusoidal and also, is phase with the fundamental source voltage.

\section{SIMULATION BLOCKS USED}

1) 3PHASE SOURCE

2) IN PORT

3) OUT PORT

4) SUBSYSTEM

5) GAIN

6) SCOPE

7) VOLTAGE MEASUREMENT

8) BREAKER

9) BUSBAR

10) CURRENT MEASUREMENT

11) GOTO BLOCK

12) FROM BLOCK

13) POWERGUI

14) RL BRANCH

15) IGBT'S 


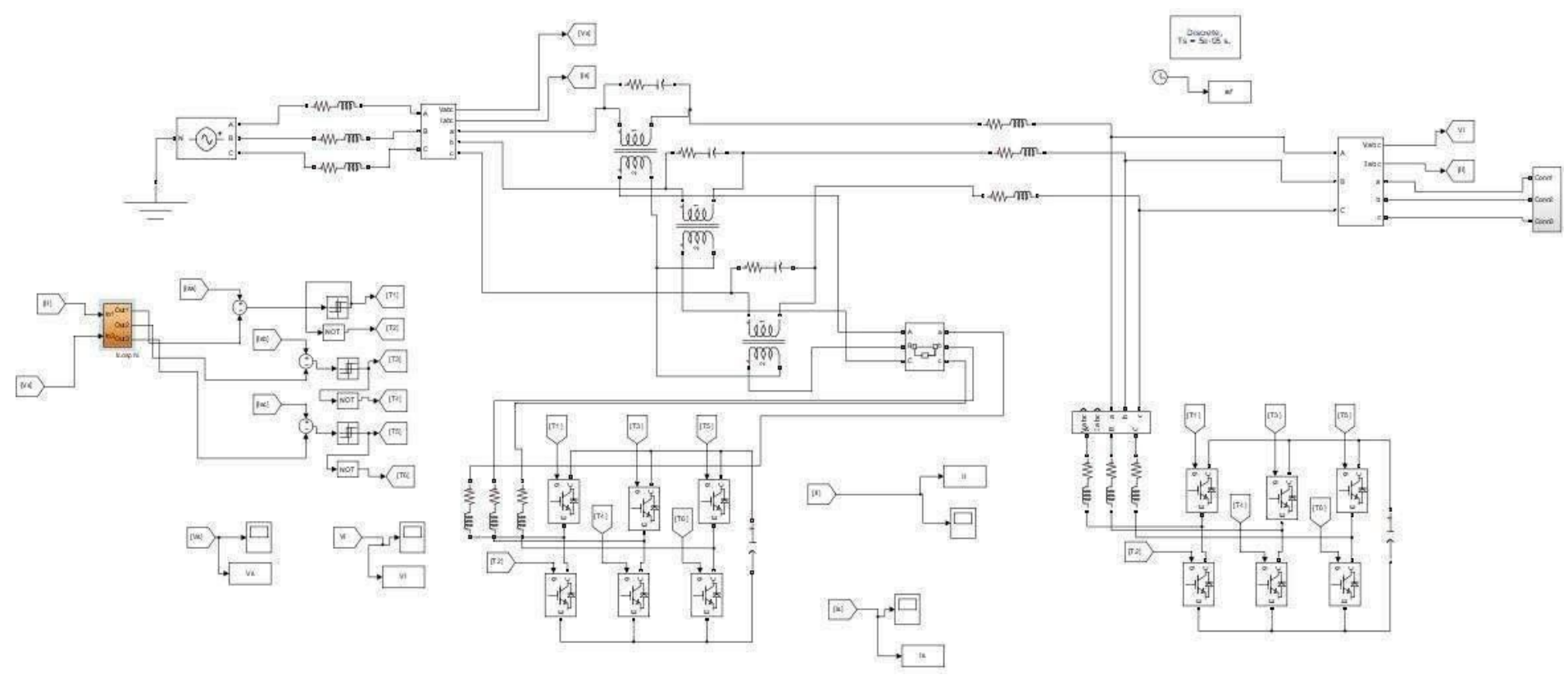

Figure:6 shows simulation block diagram

Table: 1 shows Grid parameters

\begin{tabular}{|c|c|}
\hline Grid parameters & $\begin{array}{l}\text { 3- } \emptyset, 3 \text {-wire system Source voltage }\left(\mathrm{V}_{\mathrm{S}}\right)=415 \mathrm{~V}(\mathrm{~L}-\mathrm{L}), \mathbf{5 0 H Z} \text { Source resistance }\left(\mathrm{R}_{\mathrm{S}}\right)= \\
\mathbf{1} \mathbf{\Omega} \\
\text { Source inductance }\left(\mathrm{L}_{\mathrm{S}}\right)=\mathbf{6} \boldsymbol{\mu} \mathrm{H}\end{array}$ \\
\hline Passive filter parameters & $\begin{array}{l}\text { Resistance }=0.5 \Omega \\
\text { Capacitance }=\mathbf{5} \boldsymbol{\mu} \mathbf{F}\end{array}$ \\
\hline Ripple filter Parameters & $\begin{array}{l}\text { Resistance }(\mathrm{Rf})=\mathbf{0 . 2 5} \Omega \\
\text { Inductance }(\mathrm{Lf})=\mathbf{8} \boldsymbol{\mu} \mathbf{H}\end{array}$ \\
\hline Load parameters & $\begin{array}{l}\text { Diode bridge Resistance }(\mathrm{RL})=\mathbf{1 0} \Omega \text { Inductance }(\mathrm{LL})= \\
\mathbf{2 0 0 m H} \\
\text { Asynchronous machine (squirrel cage) } \\
3.73 \mathrm{KW}, 415 \mathrm{~V}(\mathrm{~L}-\mathrm{L}), 50 \mathrm{HZ}\end{array}$ \\
\hline
\end{tabular}




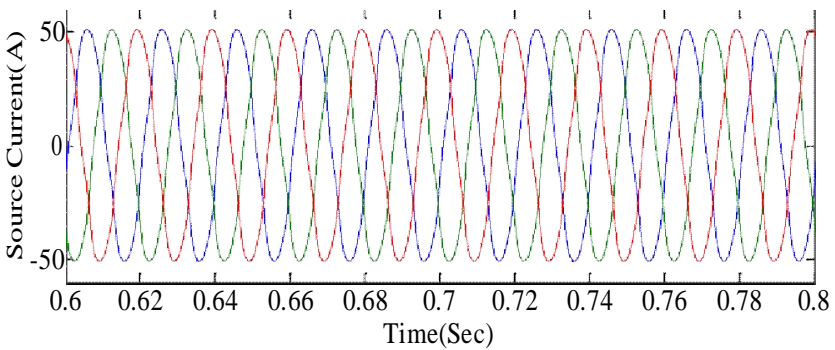

Figure:7 shows Source current

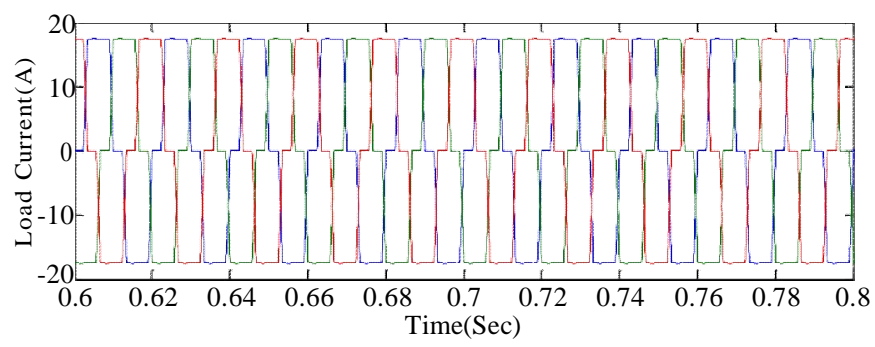

Figure:8 shows Load current

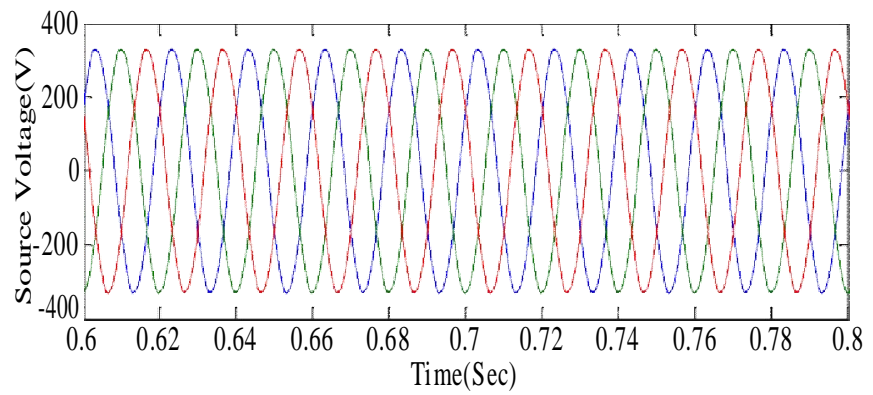

Figure:9 shows Source voltage

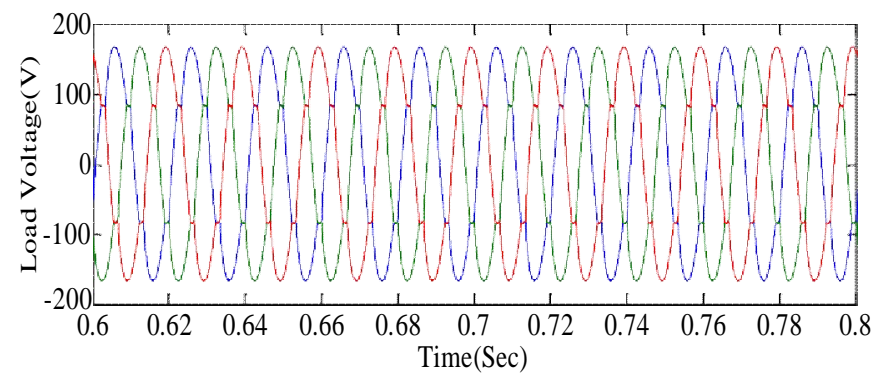

Figure:10 shows Load voltage

\section{FFT ANALYSIS}

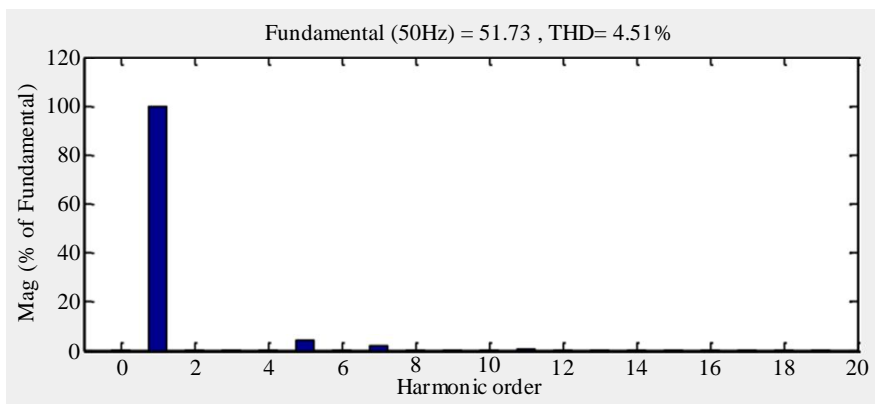

Figure:11 shows Source current

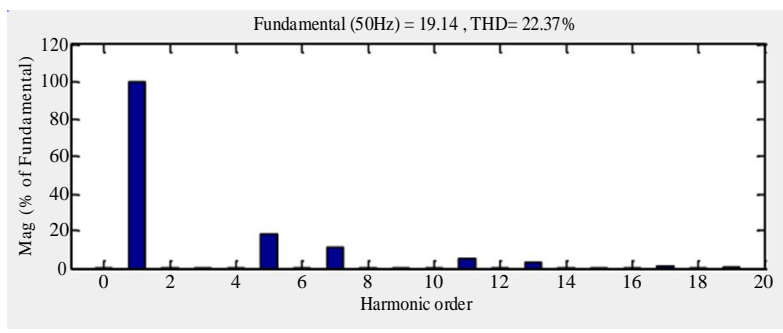

Figure:12 shows Load current

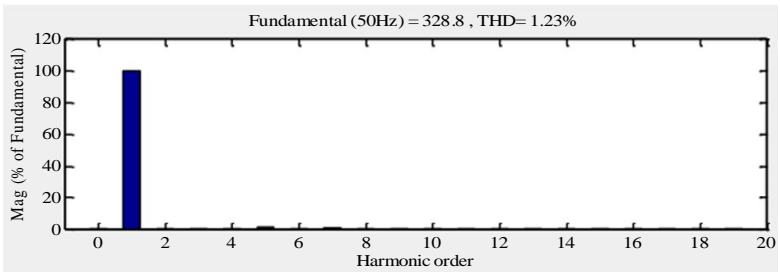

Figure:13 shows Source voltage

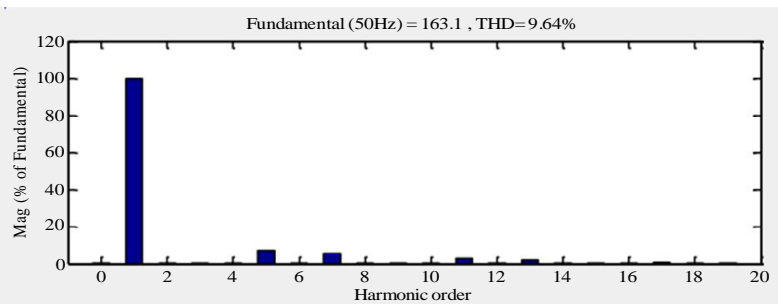

Figure:14 shows Load voltage

The THD value of the load voltage before the compensation was $22.37 \%$ it was improved to $1.23 \%$ after compensation.

The THD value of the load current before the compensation was $9.64 \%$ it was improved to $4.5 \%$ after compensation

\section{CONCLUSION}

This project describes an improved control strategy for the operation of "Unified power quality compensator" system. Several control strategy is studied like PQ theory, hysteresis current controller. The Unified power quality compensator model is simulated in MATLAB using instantaneous power theory. Shunt part of UPQC removes all the current related harmonic problems in the system and series connected part of UPQC system removes all voltage harmonics which comes up due to the use of nonlinear load. The overall Total harmonic distortion is now improved in the system which is clearly observed from the waveforms and also giving the resultant THD before and after UPQC operation. 


\section{RESULT TABLE}

Table:2 shows result analysis

\begin{tabular}{|l|c|c|}
\hline CASES & Without UPQC & With UPQC \\
\hline $\begin{array}{l}\text { SOURCE } \\
\text { VOLTAGE } \\
\text { (Mag,\% THD) }\end{array}$ & $259.8,21 \mid 30$ & $328.8,1.23$ \\
\hline $\begin{array}{l}\text { LOAD } \\
\text { VOLTAGE } \\
\text { (Mag,\%THD) }\end{array}$ & $149.2,21.48$ & $163.1,9.63$ \\
\hline $\begin{array}{l}\text { SOURCE } \\
\text { CURRENT } \\
\text { (Mag,\% THD) }\end{array}$ & $16.96,15.28$ & $51.72,4.51$ \\
\hline $\begin{array}{l}\text { LOAD } \\
\text { CURRENT } \\
\text { (Mag,\%THD) }\end{array}$ & $16.96,25.28$ & $19.13,22.36$ \\
\hline
\end{tabular}

\section{REFERENCES}

1. MB. S. Kuldeep and R. K. Kuri, "Design and Development of Soft Computing Based Unified Power Quality Conditioner for Improvement of Power Quality," 2020 IEEE International Symposium on Sustainable Energy, Signal Processing and Cyber Security (iSSSC), 2020, pp. 1-6, doi: 10.1109/iSSSC50941.2020.9358872.

2. Ivanov, M. Ciontu, D. Sacerdotianu and A. Radu, "Simple control strategy of the series filter within a unified power quality conditioner," 2017, pp. 427- 430, doi: 10.1109/SIELMEN.2017.8123362.

3. B. Sahoo, A. K. Panda, M. Mangaraj and G. M. Sahoo, "Real-Time Implementation of ALMS-NN Controlled UPQC," 2020 International Conference on Computational Intelligence for Smart Power System and Sustainable Energy (CISPSSE), 2020, pp. 1- 6, doi: 10.1109/CISPSSE49931.2020.9212214.

4. Dahono P.A, "New hysteresis current controller for threephase bridge inverters" IET journal on Power electronics, vol.2 (2009): pp. 585-594

5. H. Fujita and H. Akagi, "The unified power quality conditioner: The integration of series and shunt active filters", IEEE Trans. Power Electron, vol. 13, no. 2, pp.315$322,1998$.

6. Q. Trinh and H. Lee, "An advanced current control strategy for three phase shunt active power filters", IEEE Trans. Ind. Electron, vol. 60, no. 12, pp. 5400- 5410, Dec. 2013.

7. B. Sahoo, A. K. Panda, M. Mangaraj and G. M. Sahoo, "A Real-Time Comparative Study on the
Performances of UPQC with Different Control Algorithm," 2020 IEEE 17th India Council International Conference (INDICON), 2020, pp. 16, doi: 10.1109/INDICON49873.2020.9342172.

8. B. Sahoo, A. K. Panda, M. Mangaraj and G. M. Sahoo, "Real-Time Implementation of ALMS-NN Controlled UPQC," 2020 International Conference on Computational Intelligence for Smart Power System and Sustainable Energy (CISPSSE), 2020, pp.1-6,doi: 10.1109/CISPSSE49931.2020.9212214 